\title{
Gram Panchayat Adoption Advisor System
}

\author{
Mr. R.G.Raut \\ Assistant Professor \\ Department of I.T DVVPCOE,Ahmednar(India) \\ braut_rahul@yahoo.co.in
}

\begin{abstract}
Whenever any adopter tries to adopt the village from the website of sansad gram yojana adopter check the sorted list of villages. Sansad aadarsh gram yojana which promotes the citizen to adopt a village and work along with the community at the grass route level towards development of the villages, member of parliament, academic institutions, IT professionals, industries, NRI's, NGO's and individual volunteers are working to achieve the above mentioned goals in a participatory manner. The study describes a "Village Adoption Scheme" as a model for energizing the rural economy in India and to slow down rural-urban migration which research has shown to be harmful to both rural and urban people of India and their regions. In, gram Panchayat adoption advisor ,algorithm which is necessary is "Naïve Bays classifier algorithm". Naïve Bays algorithm is used for classification of historical data. It classifies data as poor villages get priotarized.
\end{abstract}

Keywords_Data Mining, Machine Learning, Classification Rules, Nä̈ve Bays.

$* * * * * *$

\section{IINTRODUCTION}

The village adoption study provides an opportunity to understand the factors that are responsible for underdevelopment in a village, despite plethora of programs/schemes in vogue. They also get familiar with the interventions, participatory interaction, understanding the prevailing situation, mobilization of community, initiate participatory processes ,establishing linkages among line departments etc. which are likely to strengthen the process of development and ensure poverty reduction and strengthen natural resources management. The process of village adoption is thus an experimentation and involvement of faculty members to drive the process of development in a selected village. The village adoption study envisages integrated and holistic development of village or cluster of villages selected on a micro/macro watershed basis, on an action research mode. The village adoption provides an opportunity to academicians, policy makers and civil society, to get sensitized and understand the problem and social dynamics that exists at the grass root level and assimilate the facilitating/catalysing factors responsible for building sustainable and cohesive communities through inspiring ,igniting, educating and enabling them to develop by utilizing multiple opportunities with special focus on disadvantaged sector. The village adoption will also empower the faculty for better training, research and thus rural development. This set is usually referred to as a training set, because in general, it is used to train the classification technique how to perform its classification. The classification task can be seen as a supervised technique where each instance belongs to a class, which is indicated by the value of a special goal attribute or simply the class attributes. Classification routines with data miming use a variety of algorithms and the particular algorithm used can affect the way records are classified. This work talks about decision tree classifier assumes that the presence(or absence)of a particular feature of a class is unrelated to the presence(or absence)of any other feature. Depending on the precise nature of the probability model, Naïve Bays algorithm and density based clustering can be trained very efficiently in a supervised learning setting. With the help of these two algorithms system gives the sorted list of poor villages.

\section{LITERATURE SURVEY}

The author Dr.Rajinder Singh proposes Panchayat Raj System In India.Panchayat raj institution is the grass root democracy in India. The Panchayat raj institution are considered as local self-government meant for providing basic infrastructure facilities, empowering weaker sections of the society of the society and initiate the development process at the grass-roots level of rural India .In India ,panchayat raj system is identified as the prime instrument of decentralization through which democracy becomes truly representative and responsive .From this paper the process of village adoption is taken manually but in our proposed system we give a accuracy time software for the village adoption.[1]

The author Ms.Sonali Jindal,Dr.Vinay Ojha has proposed the E-Panchayat a Revolution and gives a manual description about the Panchayat Raj System .The panchayat raj is a south Asian political system found mainly in India .E-Panchayat is a software product conceptualized,designed and developed by national informatics centre .E-panchayat has been designed 
taking into consideration all the information and knowledge management requirements in a gram panchayat .The E-PRI campaign aims to progressively support all goverments and panchayts in country to make effective use of IT in various avtivities like-improving internal management processes and decision making in panchayats .Panchayats using IT as a tool for transparency,social audit and for electronic tagging and tracking of fund transferred to panchayats. They should provided with adequate technological resources in order to be able to play a role in development.[2]

The author Leonidas Anthopoulous has proposed the Exploring Architectural and Organizational Features in Smart Cities .Smart cities is a booming international phenomenon and they suggest both a novel economic and research domain ,which is concerned from various perspectives .Recent studies illustrate that smart cities tend to evolve to green or eco-cities ,where technology is capitalized for urban sustainable growth .However, it is not clear what different architecture types are followed and how these architectures are formed .This paper investigates and compares the alternative architectures that are followed by existing smart city cases,as a means to understand how different architectures offer e-services in urban areas.[3]

The author Rutuja Somwanshi,Uthkarsha Shinde Patil has proposed the Study and Development of villages as a smart village. This paper deals with study and development of village as a smart village. Smart village is that modern energy access acts as a catalyst for development in education ,health ,security ,productive interprise .Rutuja Somwanshi said that sustainable development is generally discussed in terms of environmental considerations, but from a rural community perspective ,sustainable development must address how the people of the community generate the income to maintain their rural lifestyles.[4]

\section{PROBLEM STATEMENT}

To create lasting change in the lives of people of the villages with special focus on disadvantaged groups by sustainable and inclusive growth, with adequate opportunity for every person (villages, member of parliament, academic institution, IT professionals, industries, NRI's, NGO's and individual volunteers) to lead a useful and productive .To establish convergence models pf resources, manpower to achieve comprehensive development in tune with peoples aspirations and potential life to his or her full potential.

\section{SYSTEM ARCHITECTURE}

The proposed system is used for classifying the historical data of villages which are given by the gramsevak(user) after filling the online form.

Proposed system can be classified into five parts,
- User(Gramsevak)

- Admin

- Aopter

- Classification

- Result

User (Gramsevak) fills the information about the villages which is known as historical data.Admin does the verification of adopter and admin able to view all information at user portal and at adopter portal .Adopter fills the registration form which includes personal and professional information. Then the historical data classified for sorting of villages as per their condition .Lastly as a result the Sansad Gram Yojna(sagy/gov.) verify the credentials of adopter a nd allot the village to the adopter.

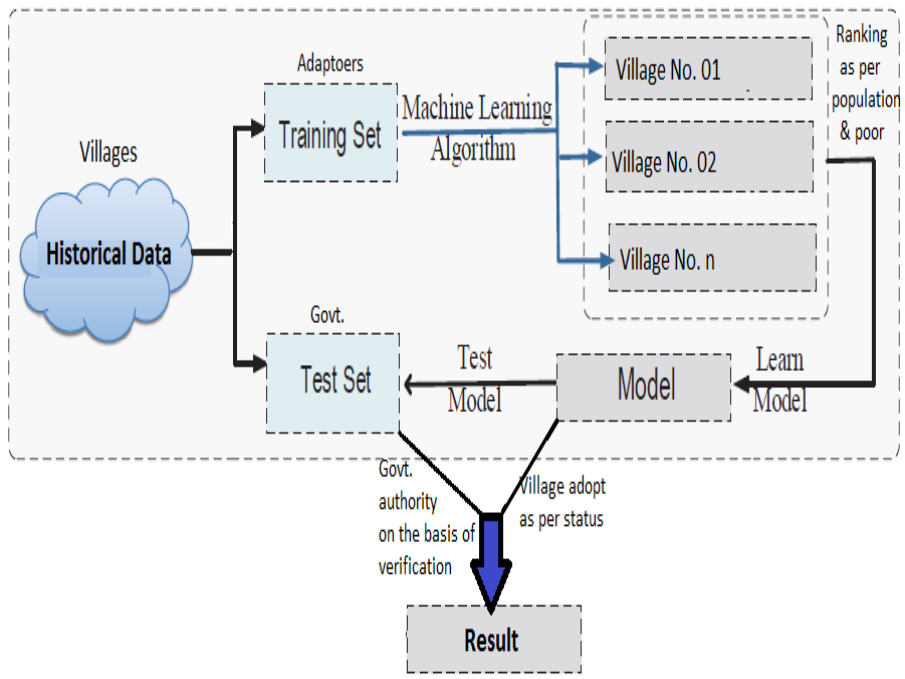

Fig. System Architecture of Proposed System

Modules :

1. User (Gramsevak)

This is the first module which fills the information about the villages .Firstly user does the registration and then able to fill the information about villages.Along with the information user puts images of villages too .Mainly user defines the condition and value of particular village .This data loaded by the user known as historical data .This type of historical data mostly store in database which is own by government.

\section{Admin}

This is the second module which is mainly known as Sansad Gram Yojna (sagy/government) which is able to see all the portals i.e user portal and adopter portal .Admin can see the list of villages loaded by user. Admin can also see the information about adopter fill by adopter by self .Admin has the authority to verify the documents related to adopter. The main working of admin is to verify the credentials of adopter Admin is the government who owns their own database in which the data about villages which is historical data and data about adopter is stored.This data can used for verification 
,cross validation ,etc .Once the verification of adopter data is done then admin gives the result i.e village is allotted or not to the adopter.

\section{Adopter}

This is the module which adopts the village for betterment of poor villages.Firstly adopter done the registration for village adoption.Adopter fills the personal and professional details like name ,profession ,net worth ,qualification ,etc .After that adopter able to see the sorted list of villages uploaded by the user(gramsevak) .Adopter requests for adoption of particular village to the sagy .Sagy verify all the information fill by the adopter .After verification sagy decides that adopter is capable or not and allot a village to adopter or not .This module includes NGO's ,NRI's , businessman ,politician, etc .

\section{Classification}

This is the main step in system .For the purpose of classification proposed system uses Naïve Bays algorithm .This algorithm is supervised learning algorithm so it gives classes before classification. This algorithm classifies the historical data which is loaded by the user. User load the information about the villages along with the relating images .This algorithm classifies the data related to villages as poor villages become at high most point in the list of villages .Finally the classification of data as the poor village become priority for adopters .

\section{Result}

Result is the last module of proposed system architecture which includes the notification which received by adopter at the end of process .Sagy(admin )verifies the credentials of the particular adopter then decide that adopter is capable for adoption or not. It gives the notification to the adopter i.e village is allotted to the adopter or not.This is the end process of the proposed system architecture.

\section{CONCLUSION AND OBSERVATION}

This study has found that gram panchayat adoption advisor has many applications and it is important field to study. This paper includes study of Sorted List of Villages and Machine learning approaches for adoption .In this paper Naïve Bays algorithm is used for the purpose of classification of historical data upload by user(gramsevak) into the sorted list in which poor villages get first priority in list .Main purpose behind this is nothing but to help the poor villages for their betterment and to help the process of adoption .It also helps to new adopters to decide whether to adopt the village or not by watching the condition of villages. This also helps in developing infrastructure facility like road, bank, transportation, medicine, computer base knowledge, electronic equipment, information technology through adoption process .It is the process which saves most of time ,money and improves the efficiency.

\section{REFERENCES}

[1] Adams, R .,Fleming, R.,Chang, C., McCarl, B., and Rosenzweig, 1993 A Re-assessment of the EconomicEffects of Global Climate Change on U.S. Agriculture,Unpublished:September.

[2] Smart village project,National Informatics center.

[3] Ms.Sonali Jindal, PGDM Student Ghaziabad,India. Dr.Vinay Ojha, Assistant Professor, Department of MBA, Ghaziabad(2016)

[4] Dr. Rajinder Singh, Department of political science, University college,Moonak-Punjab(2012).

[5] Leonidas Anthopoulous, Department of Business Administration, TEI of Thessaly ,41110 Greece(2016).

[6] Rutuja Somwanshi ,Uthkarsha Shinde Patil ,University of Aurangabad ,Maharashtra. 